\title{
The use of piles with an adjustable operation mode to restraint the shaft sinking systems' supporting structures
}

\author{
Albert Prokopov ${ }^{1, *}$, Marina Prokopova ${ }^{2}$, and Andrey Medvedev ${ }^{2}$ \\ ${ }^{1}$ Don State Technical University, 344000, Rostov-on-Don, Russia \\ ${ }^{2}$ Rostov State Transport University, 344038, Rostov-on-Don, Russia
}

\begin{abstract}
The article deals with the problem of ensuring the stability of grillages and pile foundations used to hold shaft sinking systems during the construction of vertical subway shafts. The features of such foundations' operation in the process of shaft sinking are investigated, in contrast to similar structures that receive pressure from a building under construction. The importance of taking into account the mutual influence of shaft sinking and pile foundations of the shaft sinking systems' supporting structures is shown. The design of bored piles and the technological scheme of mortar injection are proposed, which provide a change in the operating mode of pile foundations and regulation of its bearing capacity.
\end{abstract}

\section{Introduction}

Subways are an integral part of the transport systems in megalopolises and major cities, providing high speed and safety transportation of passengers with minimal negative impact on the environment. In Russia, there are currently 7 subways operating in the following cities: Moscow, St. Petersburg, Nizhny Novgorod, Novosibirsk, Samara, Yekaterinburg, Kazan and a high-speed tram system ("subway tram") with underground sections and stations in Volgograd. Work on the design and construction of subways is underway in the cities: Chelyabinsk and Krasnoyarsk. In different periods of the history of the USSR and the Russian Federation, survey and design work was carried out for the construction of subways in the cities: Rostov-on-Don, Omsk, Perm, Ufa, but these projects have not been implemented yet.

The construction of the Moscow subway is in progress at a high pace, which currently consists of more than 250 stations and is the largest in Europe and the fourth in the world in terms of the length of the lines in operation.

The complex of underground workings of the subway consists not only of the main tunnels, which include station, ferry and escalator tunnels, but also a complex network of auxiliary workings, chambers and structures that ensure the life safety, both during construction and during the subway operation, especially evacuation systems, ventilation, drainage, power supply, heating (air conditioning), alarm, communication, etc.

\footnotetext{
*Corresponding author: prokopov72@rambler.ru
} 
The most responsible and complex underground structures, both from a technical and technological points of view, are the vertical shafts that connect underground workings with the earth's surface, and have a long service life (50 years or more). The main purpose of vertical shafts in subway construction is ventilation, laying of communications, lowering and lifting of people, materials and equipment for the construction of running tunnels, drainage, etc. After the construction completion, the shafts can be mothballed or used for auxiliary purposes throughout the entire period of operation, providing fresh air supply (air supply shafts) or ejection of an outgoing air stream (ventilation shafts), laying drainage pipelines for pumping underground water with high pressure pumps from water collectors to the surface, laying power and low-current cables, etc. In some cases, vertical subway shafts can be equipped with staircase compartments and used as additional evacuation exits to the surface in case of incidents, emergencies and dangerous situations (fires, smoke, collapse of lining structures and rocks, water breakthroughs, terrorist attacks, etc.)

There are various methods and technological schemes for the construction of vertical shafts $[1,2]$, differing in the equipment of the surface for sinking, the technologies and equipment used for destruction, loading and transportation of rocks, the design of temporary and permanent lining, the sequence of the main and auxiliary technological processes. When choosing a method, technological scheme of drilling, structure of support and reinforcement of a vertical shaft, a large number of factors are taken into account, the main of which are the shaft depth and diameter, mining and geological and hydrogeological conditions of drilling, as well as the whole range of permanent, temporary and special loads, including technological and operational, and their most unfavorable combinations [2].

The design, construction and operation of subway shafts in complex mining, geological and hydrogeological conditions is an urgent scientific and technical problem, the solution of which is the main theme of this article.

\section{Methods}

The most widespread in the practice of building shafts are drilling and blasting and mechanized drilling technologies, while in the conditions of the existing urban development, the safest and most effective is the use of mechanized tunneling systems of various designs. Depending on the mining and geological conditions that determine the stability of the rock outcrops of the wellbore walls, they can be used as shaft sinking machines equipped with rock-cutting cutters and used in non-watered conditions (for example, shaft sinking type combine harvester constructions LLC «Skuratov Experimental Plant»), as well as shaft sinking systems for dispersed unstable flooded rocks, based on the use of the technology of sinking a prefabricated support ring in a "thixotropic jacket" (for example, a complex operating according to the VSM technology of Herrenknecht AG company). The latter complex has been widely used in recent years in the vertical shafts' construction of the Moscow subway [3].

One of the technological features of shaft construction using the VSM technology is the need to mount a borehole assembly, including a drilling machine and a lowering block ring, on a support structure, which transfers the load from the weight of all equipment and the support column to the soil surrounding the wellbore. For the geotechnical conditions for the construction of the Moscow subway, characterized by the presence of highly watered dispersed soils of high thickness (up to $30-40 \mathrm{~m}$ ) and underlying fractured cavernous limestones, the shaft technology construction with the immersion of the tubing lining column was used with the injection of bentonite mortar into the tubing space, which reduces the frictional force of the column and providing smooth lowering of the string under its own weight and penetration into the cutting ring bottom. 
To ensure reliable and safe operation of the support structure, it must be designed taking into account the loads transferred to it from the tunneling equipment and support and the physical and mechanical properties of the rocks containing the shaft. For the Moscow subway conditions, in most cases, grillages were used as supporting structures of the foreshaft, combining clusters of 7-10 piles, the diameter and depth of which were chosen by the calculation on finite element models (Fig. 1), based on the maximum permissible deformations.

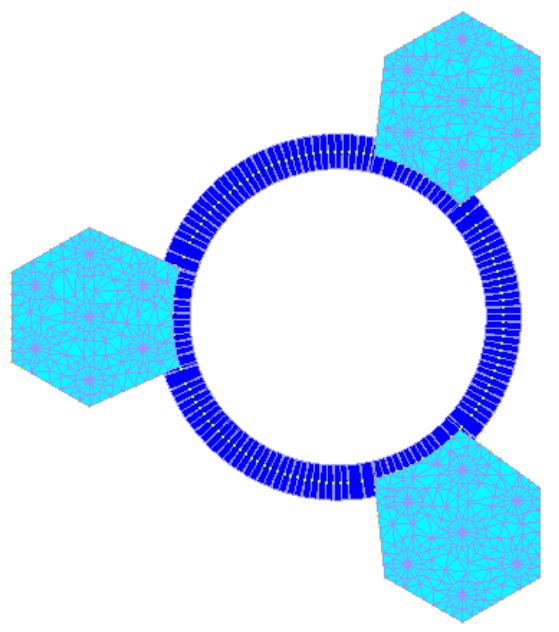

a)

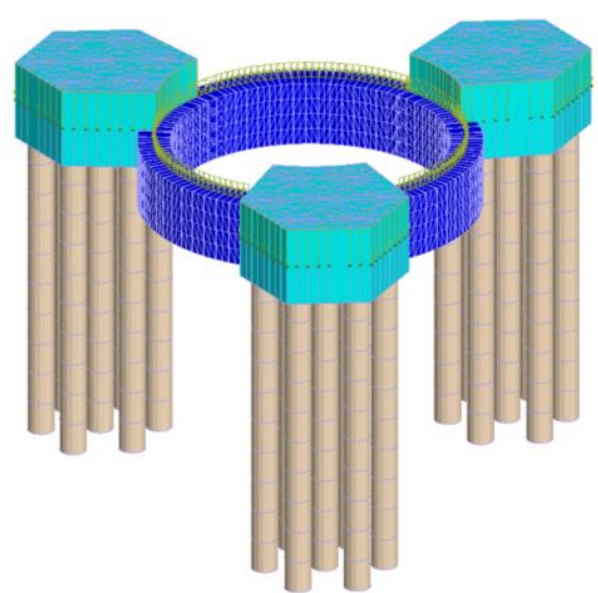

b)

Fig. 1. Finite element model of pile foundations and foreshaft of a vertical shaft: a - plan, b - general $3 \mathrm{D}$ - view

\section{Results and Discussion}

Due to the fact that solid rocky soils lie at great depths (30-35 $\mathrm{m}$ and more), the piles operating in the "hanging pile" mode were provided for the support structures of the foreshaft, their bearing capacity was provided mainly due to the frictional forces on the lateral surface and was calculated from the initial physical and mechanical properties of soils, without taking into account their possible change when driving shafts in a "thixotropic jacket". As the driving experience of the ventilation shafts in Moscow subway has shown [3], when the shaft crosses highly fractured cavernous limestones, rapid leaks can occur, both of bentonite solution from the tubing space and water from the inner section of the shaft, which provides hydraulic support and perception of the hydrostatic pressure of groundwater. In this case, along with water and bentonite, small soil particles can also be carried out into the fractured rocks from the tubing space, including from the zone of the base of the "friction piles" held by the supporting structure of the borehole complex. In case of uneven settlements of grillages piles, distortions of the lowering support ring and jamming of the drilling machine of the shaft sinking system occur [3].

Such phenomena are caused by changes in physical and mechanical properties and are similar to technogenic processes occurring during the formation and development of sinkholes on the earth's surface [4]. According to the studies [5], the main characteristics of soils that affect the risk of failure are their moisture content and strength characteristics: specific adhesion and angle of internal friction. The settlement of pile foundations is also affected by the mode of their operation and the deformation characteristics of soils lying at the base of the conditional foundation (under the "heels" of the piles). 
Fig. 2 shows the results of the stress-strain state (SSS) modeling for the system "Rock mass - pile foundations - tubing lining" at the stage of vertical shaft construction. At the same time, an emergency case described in [3] was considered, when soil decompaction occurred under one of the pile grillages and uneven deformations occurred, which led to jamming of the shaft sinking system and distortion of the support column from tubing rings.

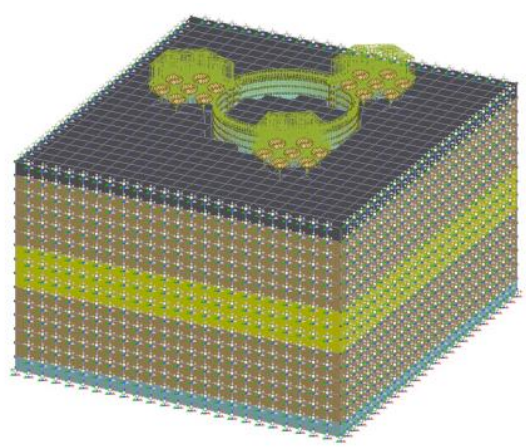

a)

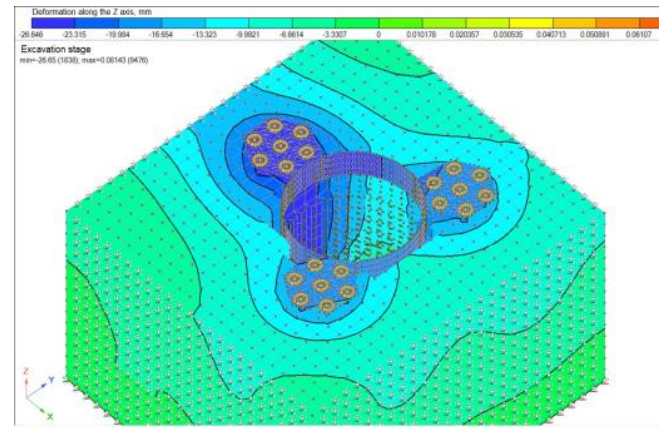

b)

Fig. 2. SSS systems "rock mass - pile foundations - tubing support" simulation at the stage of a vertical shaft construction: $a$ - general view of the model (stage of construction of the shaft), $b$ isofields of displacements along the $\mathrm{Z}$ axis

Thus, the safety and stability of the shaft sinking system support structures' pile foundations can be ensured by the controlled modes of the piles and the strength characteristics of the soils interacting with the piles.

The transfer of piles from the "hanging" mode to piles-racks can be carried out during the construction of a vertical shaft by injecting fixing mortars into the pile foundation base in order to increase the strength and deformation characteristics of the soil.

Known technological solutions for the bored pile-injector construction [6], providing for the installation together with the reinforcement cage of the pile of two injection pipes: the first is used to inject the solution into the body of the pile, the second - to fix the soil base. This approach to the manufacture of bored piles provides an increase in its bearing capacity.

In the considered case, driving a shaft by a mechanized method, the need for such a strengthening of soils may be required only in the case of the subgrade weakening during construction. In this case, it is necessary to solve successively 2 technical problems:

1) Timely record the ongoing weakening of the soil base, which will be expressed in the over-design draft of the pile grillage of the shaft sinking system supporting structure. This problem is solved by the system monitoring of pile grillages' deformations, which provides the control geodetic measurements of the geometric position for theof structures and their deviation from the design parameters. At the same time, modern approaches to geotechnical monitoring [7], used in the construction of tunnels and other underground structures, can be used, as well as monitoring methods based on the use of ground laser scanning systems [8] can be used, which will make it possible to timely and with high accuracy record uneven deformations of grillages that threaten to disrupt the normal operation of the shaft sinking system.

2) If dangerous deformations of the grillages are detected, further shaft sinking should be temporarily suspended in order to reinforce the subgrade in contact with the piles. This can be done using the well-known methods of injecting cementitious compounds into the subsoil, which are widely used to strengthen dispersed, including subsiding soils $[9,10]$. 
The choice of the strengthening method (cementation, silicatization, mudding, soil tarring, polymerization, etc.) depends on the composition and physical and mechanical properties of the soils lying in the zones of contact and interaction with piles.

To ensure the possibility of regulating the operation mode of the piles, a design shown in Fig. 3, is proposed.

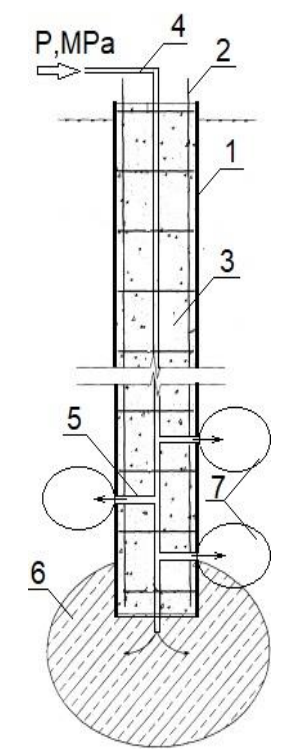

Fig. 3. Pile design with adjustable operating mode: 1 - borehole walls; 2 - reinforcement cage of the pile; 3 - pile body; 4 - hollow embedded tube for supplying cement slurry; 5 - radial tubes for solution injection; 6 - zone of soil consolidation under the pile toe bulb; 7 - areas of fastening along the lateral surface of the pile. The arrows show the direction of the slurry injection.

\section{Conclusions}

The main difference from the known reinforcement methods in the considered case of shaft sinking in highly watered dispersed soils is the construction of a bored pile with an adjustable operating mode or variable bearing capacity. This solution (Fig. 3) is provided by the device of hollow tubes: longitudinal 4 and radial 5 in the body of the bored pile 3 , through which, in the process of sinking the shaft, if necessary, it is possible to supply anchoring compounds into the soil mass: directly under the base of piles 6 and along the lateral surface of piles 7 , thereby increasing the bearing capacity of the piles and the stability of the rocks in the shaft tubing space.

Depending on the enclosing rocks' stability, the bored pile can be made directly in the well, then the role of the outer shell will be played by the vertical well walls, or in a metal casing (when driving in unstable rocks or quicksand). In the latter version, the holes are drilled in the casing, to which radial pipes are supplied for supplying cement slurry 5 .

The mode of the pile operation ("friction pile" or pile-rack) is set by the amount and pressure of the injected solution through the longitudinal tube 4 into the pile base. If there is a pile bush, as shown in Fig. 1b, under the piles toe bulbs, i.e., under the base of the conventional foundation, it is possible to form an array of sufficiently high strength and low compressibility, which will make it possible to transfer the pile cluster to the piles-racks operation mode. By injecting mortar along the lateral surface, it is possible to achieve soil compaction around each pile, filling the pores and voids with mortar, thereby increasing the 
bearing capacity of the piles themselves and ensuring an increase in strength and a decrease in the filtration coefficient in the massif containing the vertical shaft.

\section{References}

1 F. Yagodkin, M. Pleshko, A. Prokopov, Procedia Engineering 206, 293-298 (2017) doi.org/10.1016/j.proeng.2017.10.476

2. F.I. Yagodkin, A.Y. Prokopov, M.S. Pleshko, A.N. Pankratenko, IOP Conf. Series: Earth and Environmental Science 87062014 (2017) doi :10.1088/17551315/87/6/062014

3. A.Yu. Prokopov, M.V. Prokopova, Y.S. Rubtsova, A.A. Bulletin of RSTU 3(79), 145153 (2020)

4. P. Dolzhikov, A. Prokopov, V. Akopyan, Foundation Deformations Modeling in Underworking and Hydroactivated Rocks, (EMMFT 2017) Advances in Intelligent Systems and Computing, Springer, Cham 692 (2018) doi.org/10.1007/978-3-31970987-1_69

5. P. Dolzhikov, A. Prokopov, M. Prokopova, N. Hamidullina, MATEC Web of Conferences 196, 03008 (2018) doi.org/10.1051/matecconf/201819603008

6. N.F. Bulankin, Patent № 2332540 The Russian Federation, MPK E02D 5/46 (2006.01), C2. Method of erecting a bored pile-injector: № 2006128818/03: application 08.08.2006: publ. 27.08.2008. Bul. №24.

7. G. Romanova, M. Pleshko, M. Rossinskaya, A. Pankratenko, Advances in Soft Computing (2018) doi: 10.1007/978-3-319-70987-1_120

8. V.I. Kushtin, A.A. Revyakin, V.A. Sokolova, N.F. Dobrynin, Engineering Journal of Don 11 (71), 27-37 (2020). Access mode: ivdon.ru/ru/magazine/archive/ n10y2020/6665

9. A.Yu. Prokopov, I.V. Sychev, Proceedings of the Tula States University-sciences of Earth 2, 131 - 140 (2020)

10. A. Prokopov, M. Prokopova, Ya. Rubtsova, MATEC Web of Conferences. International Science Conference SPbWOSCE-2017 «SMART City» 106, 02001 (2017). doi https://doi.org/10.1051/matecconf/201710602001 